PINA, Madalena Esperança; CORREIA, Manuel. Egas Moniz (1874-1955): cultura e ciência. História, Ciências, Saúde - Manguinhos, Rio de Janeiro, v.19, n.2, abr.-jun. 2012, p.431-449.

\title{
Egas Moniz (1874-1955): cultura e ciência
}

\section{Egas Moniz (1874-1955): culture and science}

\section{Madalena Esperança Pina}

Professora da Faculdade de Ciências Médicas/ Universidade Nova de Lisboa.

Campo dos Mártires da Pátria, 130 1169-056 - Lisboa - Portugal

mpina@fcm.unl.pt

\section{Manuel Correia}

Pesquisador do Centro de Estudos Interdisciplinares do Século XX/Universidade de Coimbra. Rua Filipe Simões, 33

300-186 - Coimbra - Portugal

manuel.correia@uc.pt

\section{Resumo}

Por ocasião do sexagésimo aniversário da atribuição, em 1949, do prêmio Nobel da Medicina ou Fisiologia a Egas Moniz e a Walter Rudolf Hess, foram evocadas as circunstâncias que explicam a singular nobelização. Chama-se atenção para os traços biográficos de Egas Moniz, que são também os de muitos médicos da sua geração, asssim como dos pormenores que se prendem com o processo de nomeação e avaliação científica visando à candidatura ao prêmio Nobel. São também discutidos aspectos de ligação entre a cultura e a ciência, designadamente as controvérsias à volta do prêmio que lhe foi atribuído.

Palavras-chave: Egas Moniz (18741955); prêmio Nobel de Medicina; encefalografia arterial; angiografia cerebral; leucotomia pré-frontal.

\section{Abstract}

On the occasion of the sixtieth anniversary of the award in 1949, the Nobel Prize in Physiology or Medicine granted to Egas Moniz and Walter Rudolf Hess, the circumstances that explain the unique Nobel award require elucidation. Attention is drawn to the biographical traits of Egas Moniz, which are also those of many doctors of his generation, as well as the details which relate to the process of nomination and scientific appraisal to be eligible for the Nobel Prize. Aspects of the link between culture and science are also discussed, including the controversies surrounding the award conferred upon him.

Keywords: Egas Moniz (1874-1955); Nobel Prize in Physiology or Medicine; arterial encephalography; cerebral angiography; prefrontal leucotomy. 
$\mathrm{A}$ ntónio Caetano de Abreu Freire Egas Moniz nasceu em Avanca, Concelho de Estarreja (Portugal), a 29 de novembro de 1874. Concluiu a formatura em medicina na Universidade de Coimbra em 1899 e doutorou-se em 1901 com a tese $A$ vida sexual I, fisiologia, a que acrescentou, depois, a segunda parte, $A$ vida sexual II, patologia, que apresentou nas provas para o concurso de lente. Mais tarde foram ambas reunidas num só volume, constituindo um raro acontecimento editorial, com 19 edições, até 1933, altura em que o Estado Novo (1933-1974) limitou a sua circulação. A publicação foi colocada fora de mercado, restringida à venda nas farmácias, e obrigando à justificação do seu levantamento nas bibliotecas públicas (Correia, 2011, p.319).

Após a reforma do ensino universitário empreendida pela Primeira República (19101926), Egas Moniz tornou-se em 1911 o primeiro catedrático de neurologia e diretor do respectivo serviço no Hospital de Santa Marta, então Hospital Escolar. Desenvolveu, paralelamente, uma carreira política significativa, como parlamentar, chefe partidário e governante, até 1924. Publicou 22 livros e 242 artigos, além de numerosas conferências, ensaios biográficos, observações no domínio das artes plásticas e reflexões várias. ${ }^{1} \mathrm{O}$ seu trajeto, a um tempo, singular e geracional, oferece vários momentos de especial interesse para a história política, social e cultural de transição da Monarquia Constitucional para a Primeira República e de afirmação institucional da classe médica em Portugal.

A biografia política de Egas Moniz confunde-se com o amadurecimento das premissas culturais e ideológicas que explicam o fim do rotativismo monárquico (alternância dos dois principais partidos do sistema monárquico constitucional - o Partido Progressista, do qual Egas Moniz foi militante e deputado, e o Partido Regenerador) em que os representantes das elites políticas, entre 1878 e 1906, se revezavam no poder aplicando, no essencial, as mesmas medidas. ${ }^{2}$

Na transição da Primeira República para o Estado Novo, Egas Moniz manteve uma "distância calculada" (Antunes, 1999a, p.32) da liderança de Oliveira Salazar (1889-1970), e só retomou a atividade política pública após ter-se aposentado em 1944.

O desinvestimento de Egas Moniz na atividade política coincidiu com a emergência da ditadura militar de 1926 que pôs fim à Primeira República. De certo modo, o perfil do cientista que então começou a ser cultivado deixou deliberadamente na sombra o político que tinha sido até aquele momento (Correia, 2004).

No plano científico, salienta-se, em 1927 a apresentação pública que Egas Moniz fez, em Paris, das primeiras arteriografias pelo método de diagnóstico que começou por ser chamado 'encefalografia arterial' 3 , iniciando o processo de pesquisa e aperfeiçoamento que veio a culminar na 'angiografia cerebral'. ${ }^{4}$ Porém, foi sobretudo o fato de ter recebido o prêmio Nobel da Medicina ou Fisiologia, em 1949, juntamente com Walter Rudolf Hess $(1881-1973)^{5}$, que consolidou internacionalmente a sua imagem de cientista e desencadeou a controvérsia que perdurou até o fim do século XX acerca do conceito de psicocirurgia e dos resultados da leucotomia pré-frontal.

A evocação do cientista, na sua singularidade e nas semelhanças com figuras de outros médicos, políticos e homens de cultura do seu tempo ${ }^{6}$, serve-nos de base para um par de reflexões sobre alguns dos aspectos mais controvertidos da sua produção e afirmação 
científicas, a pretexto das comemorações do sexagésimo aniversário da atribuição do prêmio Nobel à sua pessoa.

\section{Uma cultura...}

Uma década após a atribuição do Nobel a Egas Moniz, Charles Percy Snow (1905-1980) tentou resumir e catalogar a tensão existente nos diferentes campos de produção de conhecimento, imaginando uma espécie de fronteira entre culturas, mas que, de fato, valorizava as diferenças epistemológicas entre as ciências exatas e naturais, por um lado, e as humanidades, por outro, colocando nesta última categoria aquilo a que hoje chamamos ciências sociais e humanas, mais as artes, a literatura e a filosofia (Snow, 1996). De certo modo, as ciências naturais e exatas reivindicavam uma espécie de intemporalidade, colocando, ao mesmo tempo, os seus métodos e resultados num patamar em que a legitimação universal as separava dos restantes modos de produção de conhecimentos. Três anos depois, Thomas Kuhn (1922-1996), doutorado em Física no mesmo ano em que Egas Moniz recebeu o prêmio Nobel da Medicina, publicou A estrutura das revoluções científicas (Kuhn, 1996), demonstrando como os fatores estritamente científicos (ligados a métodos, produção, interpretação e verificação dos resultados) se interligam com outros, não estritamente científicos (exercício do poder, imaginação criativa, favorecimentos e estratégias), condicionando largamente carreiras, publicações, revelação e apreciação de novas teses, bloqueando ou facilitando as mudanças de paradigma.

De certa forma, Snow (1996), ao lamentar, um tanto exageradamente, o fosso existente entre as duas culturas, exprimiu a nostalgia de um modelo de saber enciclopédico que a moderna tendência para a especialização veio fragmentar, subdividir e departamentalizar.

Apesar de raramente participar em debates públicos de caráter científico e de se escudar no tecnicismo galopante ${ }^{7}$, Egas Moniz evidenciou um pensamento que coloca a ciência na história, reconhecendo a inelutável obsolescência de todo o conhecimento. Ao lado das suas convicções monistas e organicistas, usava de uma certa abertura perante ideias novas e não via qualquer incompatibilidade entre a medicina, a investigação científica, a história e o ensaio estético e literário, tendo publicado numerosos títulos nesses diferentes gêneros.

Apesar do monismo materialista e do organicismo que determinavam a sua convicção de que a única substância cósmica de que toda a matéria é feita (monismo) torna redutível a psicologia à biologia e esta, por fim, à física (organicismo), o estudo e a adoção do hipnotismo, primeiro, e da psicanálise, depois, atestam que as suas convicções podiam ser colocadas entre parênteses quando uma nova corrente se apresentava, mesmo que aparentemente desafiasse os fundamentos da sua cosmovisão dominante. Egas Moniz tinha maior dificuldade em compaginar ciência e ética do que ciência e cultura ou ciência e história.

Como ele, praticamente todos os médicos (com ou sem produção científica conhecida) da geração de 1911 (Costa, 1999) aliam os saberes sustentados no método científico (o método das ciências naturais e exatas) aos saberes clássicos baseados na semiótica (ou nas semiologias), na filologia e na hermenêutica, largamente influenciados pelas novas correntes naturalistas. Marck Athias (1875-1946), Aníbal Bettencourt (1868-1930), Augusto Celestino da Costa (1884-1956), Francisco Gentil (1878-1964), Azevedo Neves (1877-1955) e Henrique 
de Vilhena (1879-1958), entre outros, são apontados como os founding fathers (Costa, 1999, p.33) da nova medicina portuguesa, por a terem dotado de novas bases experimentais que operaram em Portugal uma virada notável no rumo das ciências médicas.

Mais sensível à abrangência do projeto iluminista do que às clivagens intelectuais ocorridas na segunda metade do século XX, Egas Moniz escreveu com desenvoltura em registros diferenciados, recorrendo aos gêneros ensaístico, dramático e biográfico, sem se ocupar das divisões supostamente culturais que viriam a emergir depois. Moniz ligava interiormente aquilo que Snow distinguia analiticamente. A dicotomização 'cultura científica' versus 'cultura humanista' não fazia sentido para o médico cientista e escritor que publicou reflexões circunstanciadas acerca das artes plásticas, da crítica literária, da história e do teatro, além dos numerosos livros e artigos que escreveu nos domínios clínico e científico. À imagem de boa parte dos intelectuais da sua geração, Egas Moniz, sem se afastar um passo das suas convicções monistas e organicistas, conjugava a sua experiência política, literária, médica e científica sem evidenciar quaisquer tipos de separações culturais nessas diferentes matérias.

O criador da angiografia cerebral não foi dado nem ao debate nem à especulação teórica ou filosófica. Henrique Barahona Fernandes (1907-1992), psiquiatra português que com ele trabalhou, atribui-lhe "uma teoria neurônica neoassociacionista da vida mental" (Fernandes, 1966, p.72), querendo significar com isso que Egas Moniz sustentava que a repetição das respostas a dados estímulos se fixava simultaneamente na mente e, algures, na rede neuronal do sistema nervoso central. No entanto, "logo que abandonava este campo e se refugiava na arte e na literatura, era capaz do mais alado 'idealismo' e da mais empolgada sentimentalidade (provável influência 'romântica' - tipo Júlio Dinis - a cuja obra dedicou um importante estudo)" (Fernandes, 1966, p.82-83). Barahona Fernandes retrata Egas Moniz como um neurologista algo desatualizado, prisioneiro de doutrinas ultrapassadas, desvalorizando a sua adesão inicial à psicanálise.

Egas Moniz, unindo, na sua prática, o que Snow distinguiu 'culturalmente', deu prova de abertura ao hipnotismo, que valorizou e aplicou quer como auxiliar de diagnóstico psiquiátrico quer como método terapêutico (Moniz, 1925). Moniz atribuiu ao padre Faria, um religioso goense que viveu a maior parte da sua vida em França, o mérito de ter lançado os fundamentos daquilo que chamou de hipnotismo científico. Coube ao médico português também a recepção da psicanálise em meio universitário (Moniz, 1915), de difícil assimilação por alguns dos seus biógrafos. ${ }^{8}$

A neurologia, até então clínica e identitariamente ligada à psiquiatria ${ }^{9}$, deu, com Egas Moniz, passos decisivos no sentido de se afirmar como especialidade médica e se autonomizar. A reforma universitária de logo após a Revolução Republicana de 1910 incluiu, como referimos no início, a criação da cátedra de neurologia de que Egas Moniz foi o primeiro detentor. Com a especialização neurocirúrgica de Pedro Almeida Lima e outros discípulos de Egas Moniz, o campo da neurologia reforçou-se ${ }^{10}$, sem impedimento para que, no plano associativo médico, neurologistas e psiquiatras convivessem na Sociedade Portuguesa de Neurologia e Psiquiatria (SPNP), de 1949 a 1979. A autonomização progressiva da identidade dos neurologistas foi marcada pela reforma estatutária da SPNP que criou então duas seções (Neurologia e Psiquiatria). O anteprojeto foi discutido e aprovado em 1971, e posto 
em prática em 1973. Em 1977 ganhou terreno a tese da necessidade da separação da Neurologia e da Psiquiatria em duas sociedades distintas e, finalmente, em 1979, consumou-se a separação. A Sociedade Portuguesa de Neurologia (SPN) foi então instituída. Uma década depois, a original SPNP alterou a sua designação para Sociedade Portuguesa de Psiquiatria e Saúde Mental (SPPSM). Para completar a pincelada histórica, sublinhe-se que a primeira Sociedade de Psicanálise (provisória) veio a constituir-se em 1977, cerca de 62 anos após a recepção universitária da doutrina de Freud.

Quanto à neurologia, Egas Moniz, já nos seus 76 anos, ainda se esforçou por fundamentar teoricamente as bases anatômicas e a dinâmica cerebral, ocupando-se também do papel dos astrócitos que ainda recentemente foi retomado. ${ }^{11}$ Apesar de um visível défice psicopatológico na sua descrição do funcionamento do cérebro humano, que já então suscitava reservas entre neurologistas e psiquiatras, e de uma interpretação dos resultados demasiado otimista, crescentemente contestada, o prêmio Nobel, obtido em 1949, devolveulhe o ânimo que lhe escasseava em meados dos anos 1940.

\section{...e um ex-libris}

Moniz gostava de pintura e de literatura. Dedicou-se a alguma crítica de arte, estudou a loucura na pintura e prefaciou algumas obras literárias. O seu gosto pela arte e o seu espírito humanista ficaram patentes no seu ex-libris. Seu gosto por livros fê-lo adotar essa tradição, o que resultou num suporte iconográfico que espelha a sua personalidade. $\mathrm{O}$ seu ex-libris obedece à tradição bibliófila, remetendo-nos para as suas referências culturais. Na realidade, Moniz possuía duas bibliotecas, nas casas de Avanca e de Lisboa, e não foi o único médico português a criar a sua própria forma de identificar os seus livros. Adelino Vieira Neves (1976) inventariou cerca de sessenta ex-libris de médicos e de instituições ligadas à medicina. ${ }^{12}$ Os exemplares pertencentes a médicos fazem normalmente referências à heráldica familiar e aos símbolos da medicina, sendo frequente a presença da serpente. Apresentam normalmente a divisa pessoal. O ex-libris do médico Arlindo Freixo, por exemplo, foi produzido em 1949 e representa a união entre Portugal e o Brasil com a ilustração de dois monumentos, o Castelo de Beja e o Corcovado, que se unem pela serpente enrolada no bastão. A seguir, apresentamos a representação moniziana (Figura 1).

A ligação de Moniz à história ficou patente na referida imagem, na legenda alusiva a um verso do Canto V d'Os Lusíadas. "Quando da etherea gavea hum marinheiro", demonstra, nos versos de Luís de Camões, a chegada dos portugueses a terras de Oriente: "Mas já o planeta no céu primeiro/Habita cinco vezes apressada/Agora meio rosto, meio inteiro /Mostrara, enquanto o mar cortava a armada/Quando da etérea gávea um marinheiro /Pronto co a vista: 'terra terra!' brada/Salta no bordo alvoroçada a gente/Cos olhos no horizonte do Oriente" (Camões, 2000, p.219).

Uma metáfora original, patriótica e historicista talvez sejam os primeiros sinais que o olhar apreende nessa imagem. E não se trata de um acaso. O ex-libris de Egas Moniz, produzido em 1934, baseou-se num painel de azulejos produzido em 1915, da autoria de Jorge Colaço ${ }^{13}$, ilustrador e pintor de azulejos, criações nas quais deixou forte pendor historicista, com incidência em painéis históricos e camonianos. Colaço encontrou-se 




Figura 1: Ex-libris de Egas Moniz (Câmara Municipal de Estarreja; Casa Museu Egas Moniz) 
também com a medicina não pelos caminhos do exercício da profissão, mas pela encomenda que lhe foi feita para o revestimento decorativo da Sala dos Passos Perdidos da Escola Médico-cirúrgica de Lisboa, cujo edifício foi inaugurado em 1906 para a realização do Décimo Quinto Congresso Internacional de Medicina. Produziu painéis de temática médica e assistencial que se mantêm no edifício, preservados desde 1977 pela Faculdade de Ciências Médicas da Universidade Nova de Lisboa.

Desse modo, a composição central de Colaço, bem ao jeito da pintura historicista, ilustra o verso camoniano e funciona, como veremos mais adiante, como um espelho da personalidade de Moniz ou mesmo como um seu autorretrato científico e pessoal. Trata-se de um desenho que "reproduz, com luz mais intensa, a abordagem da esquadra de Vasco da Gama a Terras de Calicute do seu célebre quadro - Terra - oferecido a sua Magestade El Rey D. Manuel II" (Azevedo, 1927, p.7).

A moldura da composição remete para os valores tradicionais da arte portuguesa. A cercadura, comum ao ex-libris e ao painel de azulejos da casa de Egas Moniz, representa em trompe l'oeil aquela forma de arte, cuja presença em Portugal remonta ao século XV, em um 'casamento' de sucesso com a arquitetura e a cultura portuguesas, de forma extraordinariamente enraizada até os nossos dias. As molduras nos painéis apareceram na azulejaria do século XVIII, nomeadamente na barroca, na qual grandes composições religiosas e profanas eram emolduradas de modo exuberante. Encimam a composição duas esferas armilares, símbolos por excelência dos Descobrimentos, mas também de dom Manuel I e do seu reinado (1495-1521). Trata-se de um instrumento astronômico aplicado à navegação, conhecido pelo menos desde a China antiga, que, com a política da Expansão portuguesa, se transformou num símbolo do rei que legou à história um período áureo e à história da arte, o manuelino - estilo conhecido como tardo gótico (ou gótico tardio) português. Arquitetura, escultura e também objetos móveis ganharam, em determinados pormenores de estrutura, como janelas, colunas, arcos ou pilares, entre outros, os símbolos da época e do poder real, ou seja, motivos marítimos, alusivos à iniciativa real e à coragem de enfrentar o mar no encontro de novos caminhos e novos mundos. Um dos exemplos mais emblemáticos desse período é o Mosteiro dos Jerónimos e a particularidade dessa representação moniziana pode, na imaginação lusa, ter saído diretamente de um dos seus arcos decorados. A viagem imaginativa desde o tempo de dom Manuel I, o Venturoso, para Egas Moniz, o médico, encontra paralelo no detalhe decorativo, que se completa com duas esferas armilares rematando, lateralmente, a composição.

Assim nos permite Egas Moniz um olhar sobre suas referências familiares e pessoais ${ }^{14}$, do aio de dom Afonso Henriques, do qual herdou simbolicamente o nome, ao médico nascido em Avanca e herdeiro da família Resende, do rei venturoso e destemido ao médico que olhou como nunca os mistérios e os caminhos do cérebro. No topo da composição, os símbolos heráldicos de Moniz mostram o seu apego aos valores familiares. Trata-se de um brasão cujo escudo representa quatro famílias. No primeiro quartel, Resende, no segundo quartel, Abreu, no terceiro quartel, Freire e no quarto quartel, Pereira. O timbre remete para o apelido Valente, alusivo ao seu bisavô paterno.

O verso camoniano funciona como divisa, mas tem particular importância a utilização da expressão 'marinheiro' (Azevedo, 1927, p.7). Em primeiro lugar, pela menção a um 
período de referência na história de Portugal. ${ }^{15}$ Em segundo lugar, pela curiosidade de sabermos que a casa da sua infância em Avanca, reconstruída pelo próprio segundo projeto arquitetônico de Ernesto Korrodi, dá pelo nome de Casa do Marinheiro. Em terceiro lugar, porque Egas Moniz se consideraria, à sua maneira, um marinheiro. Destemido, corajoso, inovador e também polêmico, tal como aqueles marinheiros que durante tanto tempo enfrentaram ventos, marés, sede, fome, doença, saudade e tantas outras privações - os tais que, com coragem, mas provavelmente também com conflitos, pessoais ou institucionais (Cunha-Oliveira, Pedrosa, 2000), desbravaram novos caminhos e novo conhecimento, que desembocaram numa notável herança histórica, cultural e científica.

\section{Duas palavras sobre a leucotomia pré-frontal ${ }^{16}$}

Os valores associados à descoberta, ao desejo de um destino marcado por grandes realizações estruturaram as disposições ${ }^{17}$ que condicionaram as decisões mais importantes que Egas Moniz tomou.

O valor terapêutico da leucotomia em certas psicoses ${ }^{18}$ repare-se na formulação vaga e exclusiva - veio a ser reconhecido pelo comitê Nobel em 1949, cerca de 14 anos após as primeiras Tentativas operatórias (Moniz, 1936) ${ }^{19}$, numa fase em que boa parte dos neurocientistas de então não apenas já conhecia o método e suas variantes como, em grande medida, se tinha apercebido das limitações, contraindicações e riscos envolvidos. De fato, à medida que o método ia sendo replicado, as limitações, incertezas e, sobretudo, as alterações de personalidade que se verificavam remeteram-no para tratamento de último recurso aconselhado apenas nos casos mais desesperados. ${ }^{20}$

Quando recebeu o prêmio, Egas Moniz encontrava-se com 75 anos. Havia se aposentado cinco anos antes. Relendo a sua Última lição (Moniz, 1944), constatamos que a expressão do seu grau de regozijo é mais intensa relativamente à angiografia cerebral; Moniz consagrou menos espaço à leucotomia pré-frontal e propôs-se até, em face das numerosas (e também inesperadas) reservas contra a sua explicitação do método, a um reinvestimento na elaboração teórica de sustentação para a leucotomia pré-frontal.

Esse tipo de reparos acerca das fragilidades teóricas da leucotomia tinha ensombrado a validade das suas explicações doutrinárias praticamente desde o início. O psiquiatra Sobral$\mathrm{Cid}^{21}$ levantou objeções, revelando o seu desacordo frontal quanto à apreciação dos resultados. Onde Egas Moniz via melhoras efetivas, o amigo Sobral-Cid denunciava um período pós-operatório de melhorias ilusórias em que o "fundo psicótico" permanecia (Pereira, 2000). Essen-Möller, psiquiatra de Upsala, ao redigir a avaliação da nomeação de Moniz para o prêmio Nobel de 1944, passou em revisão os casos em que um 'mal menor' lesão ou patologia induzida - poderia resultar num 'bem maior' para o paciente, e acabou por exprimir fortes reservas quanto à possibilidade de a lesão induzida pela leucotomia préfrontal melhorar efetivamente a saúde mental dos leucotomizados; em consequência, não recomendou Moniz para o prêmio daquele ano. ${ }^{22}$

A leucotomia pré-frontal e as suas variantes haviam chegado ao conhecimento da comunidade dos neurologistas e psiquiatras no fim da década de 1930 e haviam sido avaliadas a par dos recursos psicoterápicos disponíveis (hidroterapia, choque insulínico, 
eletrochoques e injeção de pentametilenotetrazol, mais conhecido sob as variantes comercializadas de cardiazol ou metrazol). Dadas as suas fragilidades e limitações, eram aplicadas em certos casos - em 'certas psicoses' - e, tendencialmente, como 'último recurso'.

Se excetuarmos as posições mais extremadas, verificamos que, na prática clínica, o recurso à psicocirurgia estava já em evidente declínio no ano em que Moniz ganhou o prêmio Nobel da Medicina ou Fisiologia. Para além da discordância de Sobral-Cid datada de 193723, a catalogação psiquiátrica da leucotomia pré-frontal ou da lobotomia frontal como solução de último recurso, devido ao grau de incerteza dos resultados e, mormente, às alterações de personalidade, foi levantando uma densa série de oposições ao método. Mesmo Herbert Olivecrona $^{24}$, que avaliou as nomeações de Egas Moniz para o prêmio de 1949, reconheceu a seriedade das "alterações psíquicas" já então amplamente conhecidas e discutidas e que, segundo ele, deveriam colocar de sobreaviso os médicos. ${ }^{25}$

Um ano antes de morrer, Egas Moniz pronunciou-se (pela primeira vez em tais termos) sobre as linhas de argumentação pró e contra o método leucotômico. De um lado, os defensores do método sustentavam que, de um modo geral, a leucotomia beneficiava os doentes, reduzindo-lhes os estados de ansiedade e agitação e melhorando-lhes assim a qualidade de vida; por outro lado, os opositores do método sublinhavam os riscos implicados, apontando principalmente os estados de apatia e abulia subsequentes, e acima de tudo as 'alterações de personalidade' traduzidas no empobrecimento afetivo.

O texto esteve na base de uma lição proferida na Academia de Ciências de Lisboa, em maio de 1954, intitulada A leucotomia está em causa (Moniz, 1954). Moniz partiu de um inquérito sobre a leucotomia a que o jornal francês Fígaro fazia referência, reproduzindo as teses de uns e outros (a favor e contra o procedimento). Egas Moniz destacou aquilo que lhe parecia ser o apoio bem fundamentado do método, contrariado, segundo o próprio, por teses de índole religiosa, conservadora e supersticiosa. Egas Moniz, de passagem, aproveitou o ensejo para corrigir aqueles que o consideravam 'neurocirurgião'. ${ }^{26}$

Desde então, as discussões em torno da psicocirurgia (neurocirurgia funcional ou psiquiátrica) alimentaram uma prolongada controvérsia entre os que minimizavam e os que maximizavam os riscos envolvidos, cujas simplificações excessivamente personalizadas em Moniz e Walter Freeman, um dos maiores representantes do método nos Estados Unidos, se converteram, de tempos em tempos, em campanhas condenando a atribuição do prêmio Nobel a Egas Moniz, ou mesmo a sua desnobelização.

A introdução da clorpromazina na medicação psiquiátrica, por volta de 1952, alterou o quadro de terapêuticas disponíveis, e a leucotomia pré-frontal a par da lobotomia frontal passaram a ser praticadas com menor frequência e como último recurso, seguindo as conclusões do estudo de Pressman (1998) já referido.

No entanto, os exageros condenatórios da psicocirurgia parecem fazer tábua rasa da onda de esperança que a interpretação dos primeiros resultados da sua utilização levantou. Recusam o exame das terapêuticas psiquiátricas existentes à época e escamoteiam o fato de o método de Moniz ter sido replicado em quase todo o mundo e adotado, ainda que em proporções diferentes, em praticamente todos os hospitais psiquiátricos. Em face de um caso de manifesto voluntarismo terapêutico, que se apossou das comunidades médicas da década de 1940, a excessiva personalização da psicocirurgia, restringindo a res- 
ponsabilidade da sua prática a Moniz e Freeman é desaconselhável quer para entender o contexto, quer para compreender o criador do método (Moniz) e um dos seus principais defensores (Freeman). A convicção de que o método era eficaz, partilhada por ambos, estendeu-se a muitos outros médicos que foram verificando, nos casos que acompanhavam, os efeitos e os limites, a adequação e as contraindicações do seu uso.

\section{As cinco nomeações para o prêmio Nobel}

Egas Moniz começou por ser nomeado para o prêmio Nobel da Medicina ou Fisiologia em 1928. Invocaram os nomeadores, para sustentar a candidatura, os promissores resultados da encefalografia arterial - uma das primeiras designações do que viria a ser, posteriormente, conhecido por angiografia cerebral. A apresentação das primeiras arteriografias cerebrais havia sido feita em Paris, no verão do ano anterior. A esperança era grande, mas os resultados e, sobretudo, a replicação suscitou problemas que só mais tarde foram resolvidos. Contudo, os dois nomeadores ${ }^{27}$ elogiaram a obra de Egas Moniz, sublinhando o alcance dessa técnica de diagnóstico in vivo. O novo método implicava, precisamente, a diferença entre visualizar a árvore vascular cerebral, detectando deformações originadas por eventuais tumores, aneurismas, e outras malformações, ou continuar, como até então, a depender de suposições, deduções e intuições cujo grau de falibilidade era altíssimo.

Em 1933, quando da segunda nomeação para o Nobel, a técnica de diagnóstico tornarase mais conhecida. Tinha também os seus detratores, mas nos seis anos que mediavam a publicação dos primeiros resultados e essa segunda nomeação para o prêmio, Moniz havia aperfeiçoado a técnica, testado novas substâncias de contraste e adotado um dispositivo mais adequado para obter, em sequência, um maior número de radiografias. ${ }^{28}$

Quando, em 1937, Egas Moniz foi nomeado pela terceira vez, o avaliador Herbert Olivecrona (que virá a ser, curiosamente, o mesmo que o recomendará para o prêmio em 1949) repetiu a argumentação do seu antecessor de 1928 e 1933, Hans Christian Jacobaeus ${ }^{29}$, quanto a então já internacionalmente conhecida e praticada encefalografia arterial e ignorou, por completo, o fato de os nomeadores de Moniz ${ }^{30}$ destacarem, além da angiografia cerebral, a leucotomia pré-frontal, cuja primeira súmula de resultados havia sido publicada no ano anterior (Moniz, 1936). Jacobaeus explicara nas avaliações de 1928 e 1933 que, para ele, o método pneumoencefalográfico de Walter Dandy ${ }^{31}$ oferecia vantagens à encefalografia arterial (Correia, 2006, p.35) e não seria apropriado premiar Moniz, deixando Walter Dandy de fora. Egas Moniz foi, assim, duplamente prejudicado no parecer emitido por Olivecrona em 1937.32 O método angiográfico provava ser mais eficaz e, de fato, generalizou-se rapidamente, enquanto o método de Dandy caiu rapidamente em desuso; e além disso, Olivecrona passou inexplicavelmente em silêncio sobre uma das duas razões ${ }^{33}$ que levaram Moreira Júnior e Azevedo Neves a nomear Moniz naquele ano.

Tal como já foi exposto por outros autores (Antunes, 1999b; Ligon, 1998), há nas referidas avaliações das nomeações de Egas Moniz vários elementos 'exteriores' à avaliação científica. Áreas de interesse conflituais (Jacobaeus chegou a citar que havia assistentes seus a fazer experimentos similares); comparações insuficientemente balizadas (a caracterização das diferenças entre os métodos de Walter Dandy e de Egas Moniz nem sempre 
foi explícita); e, finalmente, o 'blecaute' de 1937, em que o avaliador sequer mencionou a leucotomia pré-frontal, enfatizada pelos nomeadores.

Em 1944, Essen-Möller, encarregado pelo comitê Nobel para avaliar a quarta nomeação de Moniz, prosseguiu a doutrina adotada pelos avaliadores anteriores relativamente à angiografia cerebral (a convicção de que o método de Dandy sobrelevava o método de Moniz) e discorreu sobre a leucotomia pré-frontal, já invocada, em vão, na nomeação de 1937. Para ele, não estava ainda suficientemente provado que da lesão leucotômica resultasse uma vantagem evidente. Em face dos resultados contraditórios e da controvérsia, recomendou que o comitê Nobel esperasse um pouco mais, a fim de avaliar melhor a questão. O texto de Essen-Möller é atravessado por uma reflexão bem estruturada acerca do que estava em jogo e orienta-se pelo princípio do saldo de benefícios/prejuízos que essa neurocirurgia apresentava para os pacientes.

Foi precisamente cinco anos depois, quando a leucotomia pré-frontal e a lobotomia frontal, mais bem conhecidas e testadas pelas principais instituições psiquiátricas, foram remetidas para terapêuticas de último recurso, que o comitê Nobel, sob avaliação e recomendação de Herbert Olivecrona - o mesmo avaliador que ignorou a leucotomia nas nomeações de 1937 - atribuiu, finalmente, o prêmio a Egas Moniz.

Esse fato levantou e levanta algumas questões interessantes à história e à sociologia da ciência, bem como à história da medicina.

Gráfico 1: Descobertas de Egas Moniz e nomeações para o prêmio Nobel

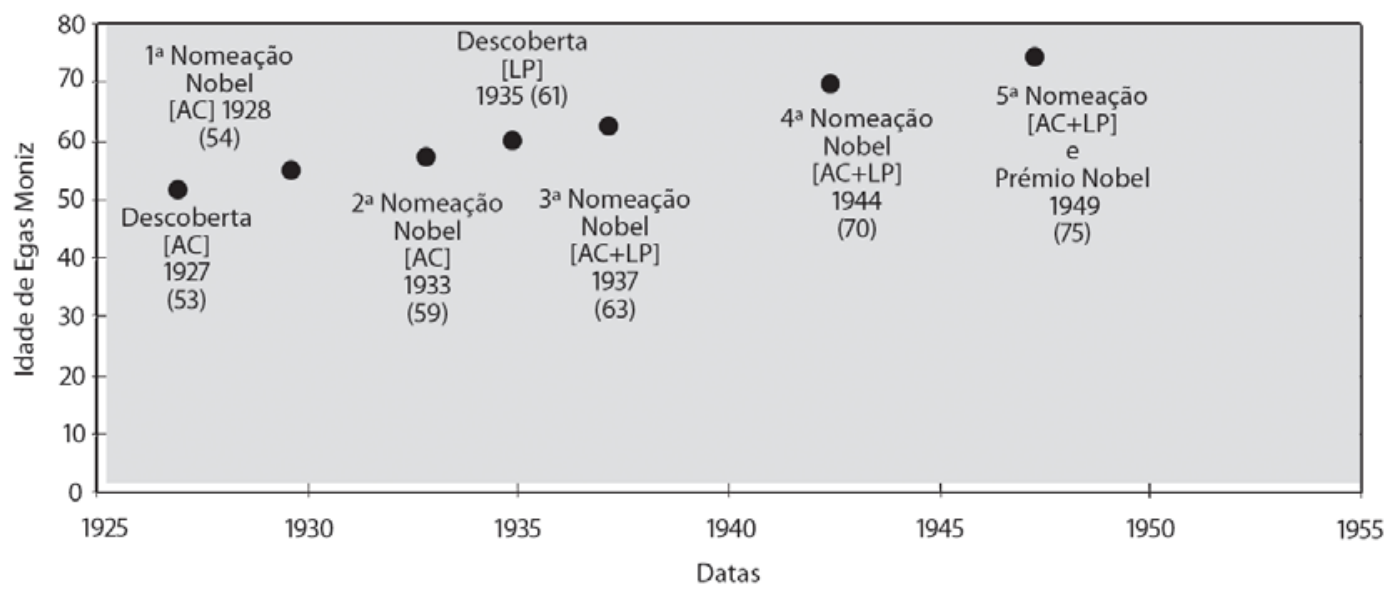

[AC]: angiografia cerebral; [LP]: leucotomia pré-frontal; entre parêntesis a idade de Egas Moniz à data

\section{A oscilação dos critérios}

Da narrativa precedente acerca das nomeações e dos pareceres avaliativos, ressalta a recusa sistemática em considerar a angiografia cerebral como uma técnica de diagnóstico inovadora, mais promissora e eficaz do que o método de Dandy. Da primeira à quinta nomeação, a angiografia cerebral surge constantemente, da parte dos nomeadores, como justificativa permanente e mais importante. Em 1945 (um ano após a aposentadoria de 
Moniz), atestando a sua consagração internacional, é-lhe descerrado o prêmio de Oslo, distinguindo-o pela descoberta e desenvolvimento da angiografia cerebral, cujo impulso na imagiologia médica foi amplamente reconhecido. Porém, resguardando-se numa comparação difusa, sob o frágil e monótono pretexto de que Moniz não deveria ser premiado pela angiografia, sem o comitê Nobel fazer também justiça a Walter Dandy, a evidência das vantagens múltiplas da angiografia foi sonegada.

Walter Dandy foi nomeado para o prêmio Nobel (em 1934 e 1936) e recusado. E Egas Moniz acabou por ganhar o prêmio por outra razão (a leucotomia). A avaliação da angiografia foi assim feita com base numa argumentação nebulosa de que só tomamos conhecimento mais de meio século depois, quando a regra do meio século de classificação secreta permite libertar parte da documentação em arquivo. A impossibilidade de os interessados debaterem abertamente o que estava em causa foi e continua a ser contrariada pelo princípio da reserva e do secretismo, levando a que a discussão sobre os termos em causa possa apenas prosseguir meio século depois das decisões tomadas. Essa cláusula do regulamento do prêmio contraria frontalmente o ethos científico. ${ }^{34}$ A manutenção em vigor desse silenciamento temporal desfavorece um debate tempestivo, suscetível de contribuir para a correção dos erros mais óbvios.

O elevado grau de aceitação da norma da classificação secreta da documentação Nobel durante o prazo de meio século explica, até certo ponto, o prolongamento dessa postura nas comunidades científicas e médicas. De fato, as polêmicas foram vistas (e são-no ainda em boa medida) como elementos perturbadores e desinteressantes para o esclarecimento de dúvidas levantadas, quer entre os que produzem conhecimento científico, quer entre os que o testam e aplicam, quer ainda para o público em geral, cujo direito de ser informado sobre as potencialidades, vantagens e inconvenientes das terapêuticas disponíveis nem sempre é respeitado.

Alguns estudos tornados conhecidos em meados do século XX atribuem aos resultados da leucotomia pré-frontal um desempenho muito mais modesto do que aquele defendido por Moniz, Freeman e outros, nos anos $1940 . .^{35}$ A apreciação confiante e voluntarista dos próprios responsáveis pelas neurocirurgias colocou a questão elementar da necessidade de uma avaliação competente e independente, acompanhando a evolução dos casos por períodos mais dilatados.

A não verificação com pressupostos de isenção e independência dificultou a interpretação dos sinais que contrariavam a visão heroica e otimista que os próprios executores das neurocirurgias davam dos resultados imediatos obtidos e contribuiram largamente para o défice de conhecimento público acerca dos prós e contras da leucotomia pré-frontal.

Há quem sustente haver um elo nas duas descobertas de Moniz, mas a coerência interna não se descortina. A primeira descoberta de Moniz filia-se à necessidade de a ciência positiva tudo mapear, localizar, descrever e mostrar. Segue na linha da prova do lipiodol (óleo de papoula iodado) de Sicard (pioneiro da mielografia), do método de contraste que Golgi criou e que Cajal ${ }^{36}$ utilizou também para fundar a nova teoria do neurônio, constituída em novo paradigma do sistema nervoso, progressivamente aceite a partir dos finais do século XIX. 
A segunda descoberta procura demonstrar que a neurologia pode oferecer soluções efetivas para alterar (melhorar) os estados de saúde mental dos doentes psiquiátricos, atuando sobre determinadas áreas do córtex. Mas o neurocirurgião apenas pode localizar a área a lesionar por cálculo aproximado. As tentativas anteriores ${ }^{37}$ não haviam sido bem-sucedidas e, por isso, essa fileira de investigação parecia distante das agendas de pesquisa da neurologia no início do século XX. O próprio Egas Moniz acentuou a diferença de pistas seguidas, ao classificar, nas suas Confidências de um investigador científico, a leucotomia e a angiografia como "dois sectores bastante afastados" (Moniz, 1949, p.307).

\section{O efeito Mateus}

Quando os cientistas franqueiam o portão da cidadela das ciências ${ }^{38}$, a receptividade dos pares aumenta gradual e proporcionalmente ao prestígio que eles vão granjeando com a divulgação dos primeiros resultados das investigações. Nesse sentido, o grau de abertura e de confiança dos neurocientistas de todo o mundo revelou-se mais atento, mais propício à replicação e mais esperançado no novo método proposto (a leucotomia pré-frontal), apesar da controvérsia que o acompanhava. Paralelamente, a forte componente experimental da cultura profissional dos médicos, orientada para resultados, interessada no alargamento da panóplia de terapêuticas disponíveis, ajuda a compreender melhor a rapidez com que a leucotomia foi examinada, experimentada e adotada nos principais hospitais psiquiátricos.

A onda de rejeição da psicocirurgia (sobretudo da lobotomia) que se levantou nos anos 1960 a par da afirmação de correntes críticas, como a antipsiquiatria, não deve ocultar o largo consenso que se registrou acerca da aceitabilidade e das alegadas vantagens terapêuticas que o comitê Nobel acabou por homologar em 1949. A importância histórica de tal consenso pode ajudar a compreender melhor a fraca expressão das vozes que se opuseram à prática da leucotomia em Portugal ou da lobotomia nos Estados Unidos. A imprensa generalista elogiava o novo método, e mesmo os psicanalistas, quer nos Estados Unidos quer em Portugal, não se lhe opunham resolutamente. ${ }^{39}$

Entretanto, o secretismo, a reserva e a dificuldade em debater com abertura e transparência os termos da investigação científica continuam como obstáculos a transpor; a personalização excessiva da psicocirurgia - concentrando a crítica em torno das figuras de Egas Moniz e Walter Freeman -, sobrecarregando a figura de Moniz com o ônus da prática generalizada da leucotomia pré-frontal e da lobotomia frontal, parece querer iludir a momentânea vaga de esperança que varreu os hospitais e clínicas psiquiátricas; e o efeito Mateus permanece como uma prática que torna mais difícil e problemática a vigilância crítica sobre os cientistas seniores.

\section{Considerações finais}

Passaram em 2009 sessenta anos sobre o evento em que Egas Moniz viu coroada a sua carreira de investigador científico com a maior distinção científica do século XX. Para compreender e conhecer melhor a história do século decorrido, ao falarmos do Moniz cientista, não seria nada rigoroso deixar no esquecimento o neurocirurgião, o político 
sagaz, o professor emérito, o médico, o sexólogo, o psicanalista, o especialista em seguros de vida, o empresário, o esteta, o ensaísta e crítico literário, o maçom, o bon vivant e o cavalheiro de duelos. Procuramos neste artigo compensar esse défice biográfico com que geralmente se amputa a representação daqueles que elevamos ao friso dos heróis. Começamos pela potência metafórica do seu ex-libris. As disposições lá plasmadas, numa representação do 'eu' que aspira a um destino de descoberta e obra distinta, podem ser verificadas, do fim para o princípio, como uma linha estratégica, uma preocupação identitária, sempre presente.

Passamos igualmente em revista a importância e o alcance das suas invenções - a angiografia cerebral e a leucotomia pré-frontal - diferenciando a consensualidade com que a angiografia se instalou nas práticas de diagnóstico e a controvérsia que a leucotomia préfrontal desencadeou.

Ao atribuir-lhe o prêmio Nobel pelo valor terapêutico da leucotomia em "certas psicoses", o comitê Nobel estava a fazer-se eco de uma parte da comunidade científica que via com bons olhos a continuação das práticas da psicocirurgia, apesar da constatação de efeitos colaterais, conhecidos e tolerados, minimizados, e justificados até meados dos anos 1950 pela inexistência de outras terapêuticas efetivas.

O comitê Nobel veio assim acrescentar um motivo mais ao interesse despertado pelas duas principais invenções de Egas Moniz, negando-lhe o prêmio pela angiografia e atribuindolho pela leucotomia. A compreensão desse paradoxo continua, portanto, a suscitar estudos e reflexões em torno de perguntas para as quais a ciência não basta e a cultura não foi até agora capaz de respostas satisfatórias.

Talvez ela apareça, se mudarmos de perspectiva, se tentarmos resolver a questão de saber por que, aos 61 anos, já nomeado duas vezes para o prêmio Nobel, aclamado internacionalmente pela influência crescente da angiografia, Moniz iniciou um novo e intricado projeto de investigação.

"Quando da etérea gávea, um marinheiro..."

\section{AGRADECIMENTOS}

Os autores agradecem a Maria de Fátima Nunes as críticas e sugestões à versão anterior deste texto. A versão que submetemos à publicação beneficiou-se muito com as suas críticas e sugestões. O resultado final responsabiliza os autores apenas. Um agradecimento especial é também devido à Câmara Municipal de Estarreja/Casa Museu Egas Moniz, pela cessão da reprodução do ex-libris de Egas Moniz

\section{NOTAS}

\footnotetext{
${ }^{1}$ A esse cômputo bibliográfico provisório devemos acrescentar mais oito capítulos em livros, introduções e prefácios; 105 conferências, alocuções e palestras; oito ensaios; dois folhetos; e 18 lições e comunicações aos pares.

${ }^{2}$ Existe uma copiosa bibliografia acerca desses temas. A título de exemplo, referimos para compreender os fatores de transição Valente, 1999; Catroga, 2000 e Homem, 1998. Sobre o poder dos médicos, ver Garnel, 2003, 2007.

${ }^{3}$ Prova de raios $\mathrm{X}$ que, mediante a injeção de líquido opacificante na carótida, permitia visualizar a rede vascular arterial do cérebro in vivo.
} 


\begin{abstract}
${ }^{4}$ Angiografia cerebral: técnica de diagnóstico que consiste na injeção de uma substância de contraste de modo a permitir radiografar o sistema vascular cerebral. O campo de aplicação desse método alargou-se, dando origem à Escola Portuguesa de Angiografia em que pontificaram Reinaldo Santos, José Pereira Caldas e Augusto Lamas (arteriografia dos membros e aortografia); Aléu Saldanha, Almeida Lima (angiopneumografia); Hernâni Monteiro, Roberto de Carvalho, Álvaro Rodrigues e Sousa Pereira (linfoangiografia); João Cid dos Santos (venografia); Sousa Pereira, Melo Adrião e Lino Rodrigues (flebografia portal) (Moniz, 1955).
\end{abstract}

${ }^{5}$ Walter Rudolf Hess, o neurofisiologista que partilhou o prêmio Nobel da Medicina ou Fisiologia, em 1949, com Egas Moniz, foi premiado pela descoberta da organização funcional do diencéfalo (interbrain) na coordenação da atividade dos órgãos. O prêmio conjunto uniu-os simbolicamente, para além da circunstância de ambos se dedicarem ao estudo do sistema nervoso, Moniz enquanto neurologista, agora empenhado no conhecimento do papel dos lobos frontais; Hess enquanto neurofisiologista dedicado ao mapeamento das áreas do diencéfalo associadas à regulação das funções neurovegetativas, circulação e pressão sanguínea etc. Contrariamente ao que seria de esperar (e se tinha visto noutros casos anteriores), fora as menções telegráficas ao fato de terem recebido o 'mesmo' prêmio no mesmo ano, verificou-se um alheamento sensível entre ambos, cujo vazio se prolongou nas narrativas biográficas posteriores. Com raríssimas e superficiais exceções, Moniz não menciona Hess, e Hess, mesmo quando, por dever de ofício, se refere à leucotomia, omite o nome de Moniz. O divórcio começou com a ausência de Moniz da cerimônia de entrega do prêmio, em Estocolmo. Moniz alegou razões de saúde para não se deslocar à Suécia (ia nos seus 75 anos, muito afetado pela gota de que sofria desde os 24 anos); recebeu o diploma, a medalha e o cheque em sua casa, em Lisboa, das mãos do embaixador sueco. Não lhes teria despertado interesse o fato de o comitê Nobel os ter premiado simultaneamente? Não teriam tido curiosidade em conhecer as investigações um do outro? Ou seria o tipo de pesquisa que cada um levava a cabo que os deixava indiferentes? O certo é que o grau de reconhecimento científico que o prêmio conjunto corporizou nunca se traduziu em sinais de reconhecimento recíproco dos dois nobelizados. Apesar de se reclamarem ambos da linhagem teórica de Pavlov; de ambos se ocuparem do estudo do sistema nervoso e de ambos navegarem no paradigma neuronal inaugurado por Ramón y Cajal, não se conhece, nem a um nem a outro, qualquer nota de divulgação acerca do teor dos trabalhos do seu par e parceiro laureado.

${ }^{6}$ Entre outros: Aquilino Ribeiro (1885-1963), Guerra Junqueiro (1850-1923) e Teixeira de Pascoaes (18771952); Mark Athias (1875-1946), Miguel Bombarda (1851-1910), Sobral Cid (1877-1941), Rui Luis Gomes (1905-1984), Abel Salazar (1889-1946), Júlio Dantas (1876-1962), Azevedo Neves (1877-1955) e Sidónio Pais (1872-1918).

${ }^{7}$ Aludimos aqui ao fechamento praticista que se foi acentuando ao longo do século XX, considerando que "O alargamento espantoso das fronteiras da ciência ao longo de todo o século XIX fez com que a visão de conjunto estabelecida pela filosofia natural se perdesse. O homem de ciência começou a interessarse muito mais pelo funcionamento dos seus instrumentos e pelos resultados das suas observações do que pela conjetura filosófica" (Fitas, Rodrigues, Nunes, 2008, p.19).

${ }^{8}$ Assinale-se que o seu biógrafo, o psiquiatra Barahona Fernandes (1983), relativiza a importância da psicanálise na reflexão e prática clínica de Egas Moniz, omitindo ou desvalorizando o próprio testemunho de Egas Moniz a esse respeito.

${ }^{9}$ Ver também no caso do Brasil o artigo de Facchinetti, Capello, Vangelista, 2010.

${ }^{10}$ Ver a esse respeito a descrição dos inícios da neurocirurgia em Portugal e da formação de Pedro Almeida Lima sob a orientação de Egas Moniz, feita por Antunes, 2010.

${ }^{11}$ A revista Science \& Vie n.1058, de novembro de 2005, era quase inteiramente dedicada aos estudos da 'massa glial' e ao alegado papel dos astrócitos - Nous avons un deuxième cerveau. O debate dessa matéria conheceu um desenvolvimento recente com a publicação, na revista Science, do artigo de Angulhon (2010).

${ }^{12} \mathrm{O}$ autor trata dos ex-libris da Biblioteca da Academia das Ciências, da Faculdade de Medicina do Porto, da Biblioteca da Escola Médico-cirúrgica do Porto e da Associação dos Médicos Portugueses, entre outros.

${ }^{13}$ O painel de Jorge Colaço encontra-se na fachada traseira da Casa do Marinheiro, a casa de família de Egas Moniz, em Avanca. Foi encomendado na altura do seu restauro, em 1915. Egas Moniz tinha particular apreço pela sua casa, planejada por Ernesto Korrodi (1870-1944), arquiteto português de origem suíça.

${ }^{14}$ Duarte (1990) identifica dois ex-libris de Egas Moniz, desenhados por Jorge Colaço e gravados a buril por André Victor Edouard Devambez. Medem 45 x 90mm e 25 x 4mm, respectivamente. 
${ }^{15}$ Note-se que essa carga mitificadora da história dos descobrimentos portugueses nas representações dos cientistas portugueses prolonga-se pelo século XX, a ponto de uma das revistas mais interessantes de história da ciência Petrus Nonius (1937) refletir abundantemente essa inclinação: "Em todos os textos [da revista Petrus Nonius] o passado nacional centrado na figura dos 'heróis', estrutura a caracterização apresentada, evidenciando uma erudição especial no que diz respeito às autoridades e às fontes primárias (impressas e manuscritas) para a História da Ciência em Portugal" (Fitas, Rodrigues, Nunes, 2008, p.224).

${ }^{16}$ A principal razão pela qual Egas Moniz continuou a ser internacionalmente referido prende-se, em simultâneo, com uma das maiores distinções científicas do século XX - o prêmio Nobel - e com a controvérsia que envolveu a razão invocada para o prêmio: a leucotomia pré-frontal, mais conhecida sob a designação de uma das suas variantes - a lobotomia frontal, ou lobotomia, tout court, - adaptada por Walter Freeman e James Watts nos Estados Unidos da América e adotada, com diferentes tonalidades de convicção e entusiasmo, em praticamente todo o mundo.

${ }^{17}$ Conceito trabalhado por Pierre Bourdieu (1979) e aqui retomado, tendo em consideração os comentários e intuições de Lahire (2005), designadamente quando estima que "a sociologia progrediria significativamente se não se contentasse em ficar na periferia dos lugares clássicos da psicologia. Não deveria, por exemplo, limitar-se ao estudo da perceção social e histórica da doença mental ou da trajetória socioinstitucional dos doentes mentais, mas sim analisar a produção social da própria doença" (Lahire, 2005, p.11).

${ }^{18}$ A expressão utilizada pelo comitê Nobel foi "for his discovery of the therapeutic value of leucotomy in certain psychoses" (Correia, 2006, p.133).

${ }^{19}$ Obra em que Egas Moniz relata os resultados de uma série de vinte leucotomias.

${ }^{20}$ Ver Pressman, 1998, que dá conta dessa avaliação no McLean Hospital (EUA).

${ }^{21}$ José de Matos Sobral-Cid (1877-1941), médico psiquiatra, colega universitário e amigo de Egas Moniz.

22 Ver "Avaliação da Candidatura de Egas Moniz de 1944", de Erik Essen-Möller citado em Correia, 2006.

${ }^{23}$ Sobral-Cid, em reunião da Sociedade Médico Psicológica de Paris (sessão de 26 de julho de 1937), após ter ouvido a exposição de Diogo Furtado, da equipe de Egas Moniz, acerca das vantagens e promessas da leucotomia pré-frontal, manifestou-se meridianamente em desacordo, apresentando uma curta comunicação intitulada "La leucotomie pré-frontale" (Sobral-Cid, 1983).

${ }^{24}$ Herbert Olivecrona (1891-1980), neurocirurgião sueco, professor de neurocirurgia do Karolinska Institutet de Estocolmo e membro do comitê Nobel.

25 “Olivecrona, Herbert. Documentos Secretos, Parecer sobre Egas Moniz, p.7 (Arquivos da Fundação Nobel, Volume de 1949, Secção III: 10)", citado por Correia (2011, p.171).

26 "Sem ter tido preparação cirúrgica, sou injustamente considerado neurocirurgião" (Moniz, 1954, p.10).

${ }^{27}$ Azevedo Neves e Bettencourt Raposo (Correia, 2006, p.35).

28 Trata-se do 'carrossel' radiológico, dispositivo proposto e montado por Pereira Caldas, que Moniz reputa fundamental para o avanço da investigação na fileira angiográfica (Moniz, 1949, p.171-172).

${ }^{29}$ Hans Christian Jacobaeus (1879-1937), médico internista, professor do Karolinska Institutet e membro do comitê Nobel.

${ }^{30}$ Moreira Júnior e Azevedo Neves (Correia, 2006, p.46).

31 Walter Edward Dandy (1886-1946), neurocirurgião norte-americano inventor da ventriculografia cerebral (prova de raios X ao cérebro após injeção de ar nos ventrículos cerebrais de modo a dilatá-los para aumentar a visibilidade das áreas cerebrais adjacentes), da qual a pneumoencefalografia era uma variante em que se procedia primeiro à drenagem de uma certa quantidade do líquido cerebrospinal.

${ }^{32} \mathrm{O}$ parecer foi traduzido na íntegra por Teresa Guerra em Egas Moniz e o prémio Nobel (Correia, 2006).

${ }^{33}$ Nas cartas de nomeação, quer de Azevedo Neves, quer de Moreira Júnior, são apontadas a angiografia cerebral e a leucotomia pré-frontal. Olivecrona, no seu relatório, discute a primeira e omite a segunda.

34 Tal visão toma, para base de reflexão, a teorização de Robert Merton (1973) acerca do ethos científico que se caracteriza pelos princípios de universalismo, comunismo, desinteresse e ceticismo organizado.

35 Ver estudo de Costa, 1957.

${ }^{36}$ Jean Sicard foi um dos mestres franceses que Moniz conheceu durante os seus estágios em França. Juntamente com Jacques Forestier utilizava desde 1921 um método de diagnóstico da medula espinhal 
que ficou conhecido por mielografia. Camilo Golgi (1843-1926) e Ramón y Cajal (1852-1934) foram dois notáveis histologistas (italiano, o primeiro; espanhol, o segundo) que ganharam em conjunto o prêmio Nobel da Fisiologia ou Medicina em 1906 pelas suas contribuições do sistema nervoso, apesar de Golgi defender a prevalência do paradigma reticular (o tecido nervoso como uma rede contínua) e Cajal afirmar o novo paradigma neuronal (o tecido nervoso composto por células autônomas e separadas).

${ }^{37}$ Damásio (2005) relata circunstanciadamente o caso de Phineas Gage, e Manjila et al. (2008), as experiências de Burkhardt.

${ }^{38}$ Recordamos aqui o "efeito Mateus", descrito por Robert Merton (1968), para significar o elevado grau de probabilidade de a comunidade científica reconhecer e avaliar mais fácil e favoravelmente o trabalho de um cientista mais conhecido do que um trabalho de um menos conhecido, ainda que de mérito semelhante. Merton está a pensar precisamente nos prêmios científicos (com particular destaque para o prêmio Nobel). Para nomear o 'efeito' inspira-se no Evangelho segundo Mateus (25:29): "Porque a todo o que tem se lhe dará, e terá em abundância; mas ao que não tem, até o que tem lhe será tirado" (Bíblia Sagrada, 2002).

${ }^{39}$ Para uma visão de conjunto quanto à prática da psicocirurgia nos principais hospitais psiquiátricos dos Estados Unidos, ver Pressman, 1998. Quanto ao papel da imprensa na promoção das supostas virtudes da lobotomia, ver Diefenbach, 1999. Para ilustrar a amplitude do consenso que ajuda a explicar a falta de veemência na oposição à leucotomia e à lobotomia, quer da parte de neurologistas e neurocirurgiões, quer de psiquiatras e psicanalistas, ver Raz, 2008.

\section{REFERÊNCIAS}

ANGULHON, Cendra et al.

Hippocampal short- and long-term plasticity are not modulated by astrocyte $\mathrm{Ca}^{2+}$ signaling. Science, Washington, v.327, n.5970, p.1250-1254. 2010.

ANTUNES, João Lobo.

Egas Moniz. Uma biografia. Lisboa: Gradiva. 2010.

ANTUNES, João Lobo.

Egas Moniz: uma palavra sobre o Outro. In: Alves, Manuel Valente (Ed.). O ensino médico em Lisboa no início do século: sete artistas contemporâneos evocam a geração médica de 1911. Lisboa: Fundação Calouste Gulbenkian. 1999a.

ANTUNES, João Lobo.

Egas Moniz na investigação científica. In: Melo, António Rocha et al. Homenagem a Egas Moniz. Porto: Fundação de Serralves. 1999b.

AZEVEDO, Conde de.

O ex-libris do Dr. Egas Moniz. Revista de ex-libris portugueses, Lisboa. Separata do v.6. 1927.

BÍBLIA.

Bíblia sagrada. Lisboa: Difusora Bíblica; Franciscanos Capuchinhos. 2002.

BOURDIEU, Pierre.

La distinction: critique sociale du jugement. Paris: Minuit. 1979.

CAMÕES, Luís de.

Os Lusíadas. $4^{\text {a }}$ ed. Lisboa: Ministério dos

Negócios Estrangeiros. Instituto Camões, 2000.
CATROGA, Fernando.

O republicanismo em Portugal: da formação ao 5 de Outubro de 1910. Lisboa: Notícias. 2000.

CORREIA, Manuel.

Egas Moniz: representação, saber e poder. Tese

(Doutorado) - Faculdade de Letras,

Universidade de Coimbra, Coimbra. 2011.

CORREIA, Manuel.

Egas Moniz e o prémio Nobel: enigmas, paradoxos e segredos. Coimbra: Imprensa da Universidade. 2006.

CORREIA, Manuel.

O político na sombra do cientista: (1)

Considerações acerca da importância e do alcance de dois enigmas monizianos, o 'periférico' e o 'político'. Vértice, Lisboa, v.10, n.119, p.57-74. 2004.

COSTA, Jaime Celestino da.

A geração médica de 1911. In: Alves, Manuel Valente (Ed.). O ensino médico em Lisboa no início do século: sete artistas contemporâneos evocam a geração médica de 1911. Lisboa: Fundação Calouste Gulbenkian. p.29-62. 1999.

COSTA, Nunes da.

Catamnèse de 197 leucotomies. Anais

Portugueses de Psiquiatria, Lisboa, v.9, n.9. p.1479. 1957.

CUNHA-OLIVEIRA, José; PEDROSA, Aliete. Quando da ethérea gávea hum marinheiro. In: Pereira, Ana Leonor; Pita, João Rui (Org.). Egas Moniz em livre exame. Coimbra: Minerva, p.177219. 2000. 
DAMÁSIO, António.

O erro de Descartes. Lisboa: Europa-América. 2005.

DIEFENBACH, Gretchen J. et al.

Portrayal of lobotomy in a popular press, 1935-1960. Journal of the History of

Neurosciences, London, v.8, n.1, p.60-69. 1999.

DUARTE, Sérgio Avelar.

Ex-libris portugueses heráldicos. Porto: Livraria Civilização. 1990.

FACCHINETTI, Cristiana; CAPELLO, Priscilla; VANGELISTA, Danielle Ferreira.

Arquivos Brasileiros de Psiquiatria, Neurologia e Ciências Afins: uma fonte com muita história. História, Ciências, Saúde - Manguinhos, Rio de Janeiro, v.17, supl.2, p.527-535. 2010.

FERNANDES, Henrique J. de Barahona. Egas Moniz: pioneiro dos descobrimentos médicos. Lisboa: ICLP, 1983.

FERNANDES, Henrique J. de Barahona. Filosofia e psiquiatria. Coimbra: Atlântida. 1966.

FITAS, Augusto J.S.; RODRIGUES, Marcial A.E.; NUNES, Maria de Fátima.

Filosofia e história da ciência em Portugal no século XX. Casal de Cambra: Caleidoscópio. 2008.

GARNEL, Maria Rita Lino.

Vítimas e violências na Lisboa da I República. Coimbra: Imprensa da Universidade. 2007.

GARNEL, Maria Rita Lino.

O poder intelectual dos médicos: finais do século XIX - inícios do século XX. Coimbra:

Faculdade de Letras. 2003.

HOMEM, Amadeu Carvalho.

Monarquia Constitucional e rotativismo político. Madrid: Comisaría General de España. 1998.

KUHN, Thomas S.

The structure of scientific revolutions. Chicago: The University of Chicago Press. 1.ed., 1962. 1996.

LAHIRE, Bernard.

Patrimónios individuais e disposições. Para uma sociologia à escala individual. Sociologia, problemas e práticas, Lisboa, v.10, n.49, p.11-42. 2005.

LIGON, B. Lee.

Biography: history of developments in imaging techniques: Egas Moniz and angiography.

Seminars in Pediatric Infectious Diseases, Philadelphia, v.14, n.2, p.173-181. 2003.

LIGON, B. Lee.

The mystery of angiography and the

"anwarded" Nobel Prize: Egas Moniz and Hans
Christian Jacobaeus legacy. Neurosurgery, Atlanta, v.43, n.3, p.602-611. 1998.

MANJILA, Sunil et al.

Modern psychosurgery before Egas Moniz: a tribute to Gottlieb Burkhardt. Neurosurgery

Focus, Charlottesville, v.25, n.1, p.1-4. 2008.

MERTON, Robert K.

The normative structure of science. In: Merton, Robert K. The sociology of science: theoretical and empirical investigations. Chicago: The University of Chicago Press. p.267-278. 1973.

MERTON, Robert K.

The Matthew effect in science. Science, Washington, v.159, n.3810, p.56-63. 1968.

MONIZ, Egas.

Subsídios para a história da angiografia.

A Medicina Contemporânea, Lisboa, v.73. n.7, p.329-346. 1955.

MONIZ, Egas.

A leucotomia está em causa. Lisboa: Academia de Ciências de Lisboa. (Biblioteca de Altos Estudos). 1954.

MONIZ, Egas.

Confidências de um investigador científico. Lisboa: Ática. 1949.

MONIZ, Egas.

A última lição. Lisboa: Portugália. 1944.

MONIZ, Egas.

Tentatives opératoires dans le traitement de certaines psychoses. Paris: Masson. 1936.

MONIZ, Egas.

O padre Faria na história do hipnotismo. Lisboa: Faculdade de Medicina. 1925.

MONIZ, Egas.

As bases da psicanálise. (Lição do Curso de Neurologia da Faculdade de Medicina de Lisboa). A Medicina Contemporânea, Lisboa, v. 32, n.47, p.377-383. 1915.

NEVES, Adelino Vieira.

O ex-libris e o seu uso pelos médicos portugueses. Braga: Academia Portuguesa de Ex-Libris. 1976.

PEREIRA, José Morgado.

O início da leucotomia em Portugal e a querela entre Egas Moniz e Sobral Cid. In: Pereira, Ana Leonor; Pita, João Rui (Org.). Egas Moniz em livre exame. Coimbra: Minerva. p.151-161. 2000.

PRESSMAN, Jack D.

Last resort: psychosurgery and the limits of medicine. Cambridge: Cambridge University Press. 1998. 
RAZ, Mical.

Between de ego and the icepick: psychosurgery, psychoanalysis and psychiatric discourse.

Bulletin of the History of Medicine, Baltimore, v.82, n.2, p.387-420. 2008.

SNOW, Charles Percy.

As duas culturas. Lisboa: Presença. 1.ed., 1959. 1996.
SOBRAL-CID, José de Matos.

Obras. v.1. Lisboa: Fundação Calouste Gulbenkian. 1983.

VALENTE, Vasco Pulido.

O poder e o povo: a revolução de 1910. Lisboa: Gradiva. 1999.

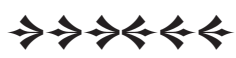

